Beth Careyva, MD; Grant Greenberg, MD, MA, MHSA; Katarzyna Jabbour, PharmD, BCPS; Nicole Defenbaugh, PhD Lehigh Valley Health Network, Allentown, PA

Joan Nashelsky, MLS Family Practice Inquiries Network, lowa City

DEPUTY EDITOR Rick Guthmann, MD, MPH

Advocate Illinois Masonic Family Medicine Residency, Chicago

\title{
Q/ Do cinnamon supplements improve glycemic control in adults with T2DM?
}

\section{EVIDENCE-BASED ANSWER}

\begin{abstract}
A THE ANSWER ISN'T CleAr. Cinnamon supplements for adults with type 2 diabetes haven't been shown to decrease hemoglobin AlC (strength of recommendation [SOR]: C, multiple systematic reviews of disease-oriented outcomes).

Cinnamon supplements have shown
\end{abstract}

\section{Evidence summary}

A 2013 systematic review of 10 randomized controlled trials (RCTs) with a total of 543 patients with type 2 diabetes evaluated the effect of cinnamon $(120 \mathrm{mg} / \mathrm{d}$ to $6 \mathrm{~g} / \mathrm{d})$ on measures of glycemic control. ${ }^{1}$ Study duration ranged from 4 to 18 weeks. Fasting glucose levels demonstrated small but statistically significant reductions $(-24.6 \mathrm{mg} / \mathrm{dL}$; 95\% confidence interval [CI], -40.5 to -8.7 $\mathrm{mg} / \mathrm{dL}$ ), whereas hemoglobin AlC levels didn't differ between treatment and control groups $(-0.16 \%$; $95 \% \mathrm{CI},-0.39 \%$ to $0.02 \%)$. Study limitations included heterogeneity of cinnamon dosing and formulation and concurrent use of oral hypoglycemic agents.

\section{Studies of glycemic control produce mixed results}

A 2012 systematic review of 10 RCTs comprising 577 patients with type 1 (72 patients) or type 2 (505 patients) diabetes evaluated the effects of cinnamon supplements (mean dose, $1.9 \mathrm{~g} / \mathrm{d}$ ) on glycemic control compared with placebo, active control, or no treatment. ${ }^{2}$ Study duration ranged from 4.3 to 16 weeks (mean, 10.8 weeks). Studies evaluating hemoglobin AlC lasted at least 12 weeks. inconsistent effects on fasting glucose levels (SOR: C, multiple systematic reviews and a single meta-analysis of disease-oriented outcomes). Supplements decreased fasting glucose levels in some studies, but the evidence isn't consistent and hasn't been correlated with clinically significant improvements in glycemic control.
Fasting glucose as measured in 8 studies (338 patients) and hemoglobin A1C as measured in 6 studies (405 patients) didn't differ between treatment groups (mean fasting glucose difference $=-0.91 \mathrm{mmol} / \mathrm{L} ; 95 \% \mathrm{CI}$, -1.93 to 0.11 ; mean hemoglobin A1C difference $=-0.06 ; 95 \% \mathrm{CI},-0.29$ to 0.18 ). The risk for bias was assessed as high or unclear in 8 studies and moderate in 2 studies.

A 2012 systematic review and metaanalysis of 6 RCTs including 435 patients with type 2 diabetes evaluated the impact of cinnamon supplements ( 1 to $6 \mathrm{~g} / \mathrm{d}$ ) on glycemic control. ${ }^{3}$ Participants consumed cinnamon for 40 to 160 days. Hemoglobin AlC decreased by $0.09 \%$ ( $95 \%$ CI, $0.04 \%$ to $0.14 \%$ ) in 5 trials (375 patients), and fasting glucose decreased by $0.84 \mathrm{mmol} / \mathrm{L}$ (CI, 0.66 to 1.02 ) in 5 trials (326 patients). Study limitations included heterogeneity of cinnamon dosing and study population.

\section{Recommendations}

The American Diabetes Association finds insufficient evidence to support the use of herbs or spices, including cinnamon, in treating diabetes. ${ }^{4}$ 


\section{$>$}

\section{Consider biopsy to rule out malignancies in large scalp lesions.}

\section{Diagnosis: \\ Cherry hemangioma}

A benign hemangioma was suspected; however, given its unusually large size and uncharacteristic location, other entities such as amelanotic melanoma and lobular capillary hemangioma (pyogenic granuloma) needed to be ruled out. Pathology following a shave excision (with electrocautery) confirmed that this was a cherry hemangioma.

Cherry hemangiomas, also known as senile hemangiomas or Campbell de Morgan spots, are a nearly ubiquitous benign vascular proliferation that increase in frequency and number with age. ${ }^{1,2}$ They also have been associated with pregnancy and some chemical exposures. ${ }^{3,4}$ In general, they are of no clinical consequence. Typically, they are 1- to 5-mm bright pink or bright to dark red papules located on the arms and trunk, a description that has persisted since at least $1947 .{ }^{1}$ Scalp involvement is considered rare. ${ }^{5}$

\section{Differential includes malignant entities}

The large size of the lesion in addition to its unusual location on the scalp prompted consideration of a malignant entity despite many features of a benign process.

- Amelanotic melanomas classically are described as flesh-colored, but up to $70 \%$ of amelanotic melanomas may actually be red. Red amelanotic melanomas may account for nearly $4 \%$ of all melanomas and frequently are underrecognized. ${ }^{6}$ Pathology ruled out melanoma for this patient.

- Lobular capillary hemangiomas (also known as pyogenic granulomas) typically manifest as rapidly growing, painless, friable papules or nodules in young adults and adolescents. Cutaneous lobular capillary hemangiomas are most often located on the head and neck, nose, face, extremities, and upper trunk. These benign lesions may grow to several centimeters in diameter and are prone to bleeding and ulceration, which this patient notably did not have. ${ }^{7}$

\section{Treatment often isn't required}

Most cherry hemangiomas are asymptomatic and small enough that they don't catch on clothing or jewelry. For larger lesions, shave excision with or without electrocautery of the base may be performed. Curettage and laser therapy also have been used with success. ${ }^{5}$

- The patient in this case had no recurrence or development of new cherry hemangiomas 2 years after her scalp lesion was removed.

JFP

\section{CORRESPONDENCE}

J. Lane Wilson, MD, East Carolina University Family Medicine, 101 Heart Drive, Greenville, NC 27834; wilsonjo@ecu.edu

\section{References}

1. Murison AR, Sutherland JW, Williamson AM. De Morgan spots. Br Med J. 1947;1:634-636.

2. Plunkett A, Merlin K, Gill D, et al. The frequency of common nonmalignant skin conditions in adults in central Victoria, Australia. Int J Dermatol. 1999;38:901-908.

3. Firooz A, Komeili A, Dowlati Y. Eruptive melanocytic nevi and cherry angiomas secondary to exposure to sulfur mustard gas. J Am Acad Dermatol. 1999;40:646-647.

4. Raymond LW, Williford LS, Burke WA. Eruptive cherry angiomas and irritant symptoms after one acute exposure to the glycol ether solvent 2-butoxyethanol. J Occup Environ Med. 1998;40:10591064

5. Kim JH, Park H, Ahn SK. Cherry angiomas on the scalp. Case Rep Dermatol. 2009;1:82-86.

6. McClain SE, Mayo KB, Shada AL, et al. Amelanotic melanomas presenting as red skin lesions: a diagnostic challenge with potentially lethal consequences. Int J Dermatol. 2012;51:420-426.

7. Usatine R. Pyogenic granuloma. The Color Atlas of Family Medicine. New York, NY: McGraw-Hill Medical; 2009:666-669.

\section{CLINICAL INQUIRIES}

CONTINUED FROM PAGE 260

\section{Editor's Takeaway}

Meta-analyses of multiple small, lowerquality studies yield uncertain conclusions.
If cinnamon does improve glycemic control, the benefit is minimal-but so is the risk.
References

1. Allen RW, Schwartzman E, Baker WL, et al. Cinnamon use in type 2 diabetes: an updated systematic review and meta-analysis. Ann Fam Med. 2013;11: 452-459.

2. Leach MJ, Kumar S. Cinnamon for diabetes mellitus. Cochrane Database Syst Rev. 2012;(9):CD007170. 3. Akilen R, Tsiami A, Devendra D, et al. Cinnamon in glycaemic con-
trol: systematic review and meta-analysis. Clin Nutr. 2012;31:609-
615 .
4. American Diabetes Association. Standards of medical care in dia-
betes-2017. 4. Lifestyle management. Diabetes Care. 2017;40(suppl 1):S33-S43. 